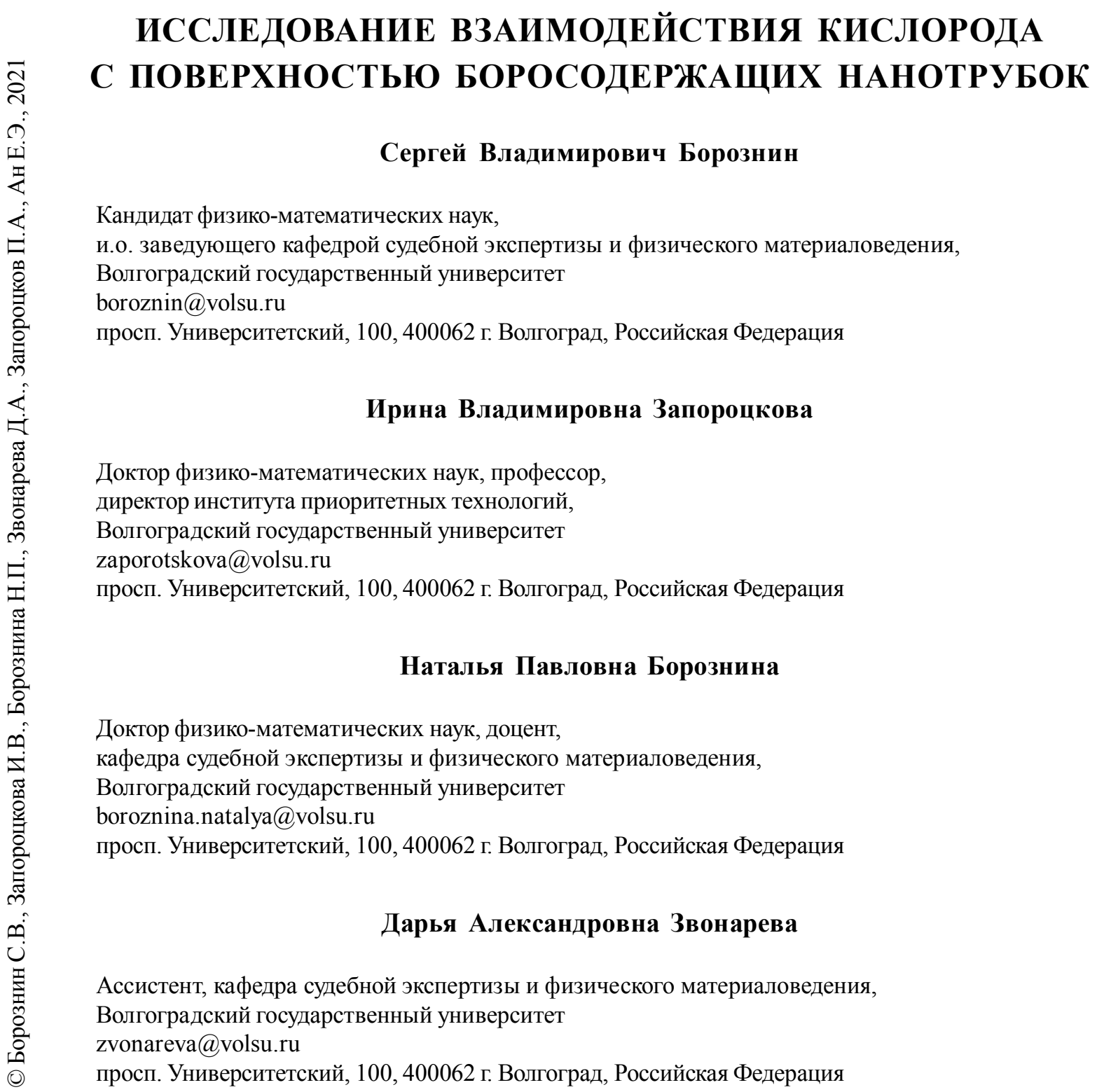

\section{Сергей Владимирович Борознин}

Кандидат физико-математических наук,

и.о. заведующего кафедрой судебной экспертизы и физического материаловедения, Волгоградский государственный университет boroznin@volsu.ru просп. Университетский, 100, 400062 г. Волгоград, Российская Федерация

\section{Ирина Владимировна Запороцкова}

Доктор физико-математических наук, профессор, директор института приоритетных технологий, Волгоградский государственный университет zaporotskova@volsu.ru просп. Университетский, 100, 400062 г. Волгоград, Российская Федерация

\section{Наталья Павловна Борознина}

Доктор физико-математических наук, доцент, кафедра судебной экспертизы и физического материаловедения, Волгоградский государственный университет boroznina.natalya@volsu.ru просп. Университетский, 100, 400062 г. Волгоград, Российская Федерация

\section{Дарья Александровна Звонарева}

Ассистент, кафедра судебной экспертизы и физического материаловедения, Волгоградский государственный университет zvonareva@volsu.ru просп. Университетский, 100, 400062 г. Волгоград, Российская Федерация 


\section{Павел Александрович Запороцков}

Кандидат физико-математических наук, доцент,

кафедра судебной экспертизы и физического материаловедения,

Волгоградский государственный университет

zaporotskov@volsu.ru

просп. Университетский, 100, 400062 г. Волгоград, Российская Федерация

\section{Евгения Эдуардовна Ан}

Студент, кафедра судебной экспертизы и физического материаловедения,

Волгоградский государственный университет

NIm-201_291179@volsu.ru

просп. Университетский, 100, 400062 г. Волгоград, Российская Федерация

Аннотация. Рассматриваются результаты исследования взаимодействия атомарного и молекулярного кислорода с внешними поверхностями бор-углеродных $\left(\mathrm{BC}_{3}\right)$, бор-нитридных (BN) и борных нанотрубок: типа «кресло» $(\mathrm{n}, \mathrm{n})$ и «зигзаг» $(\mathrm{n}, 0)$. Исследование выполнено методом MNDO в рамках модели ковалентно-циклического кластера с внедренными ионами. Определена оптимальная геометрия адсорбционных комплексов и описаны их основные электронные и энергетические свойства. Было доказано, что бор-углеродные нанотрубки являются лучшими адсорбентами кислорода по сравнению с другими рассматриваемыми типами нанотрубок.

Ключевые слова: ab initio, углеродные нанотрубки, адсорбция, бор-углеродные нанотрубки, кислород, бор-нитридные нанотрубки, окисление, MNDO.

Исследования полупроводниковых углеродных нанотрубок показывают, что они чрезвычайно чувствительны к химической среде, а воздействие кислорода резко меняет их свойства [7]. Поскольку другие типы тубуленов [2], например бороуглеродные нанотрубки типа $\mathrm{BC}_{3}$ [5] и боронитридные $\mathrm{BN}$ нанотрубки [8], вызывают большой интерес, представляется важным исследовать, способны ли они поглощать атомарный и молекулярный кислород. Исследование проводилось с использованием полуэмпирического метода квантового расчета молекулярной электронной структуры в вычислительной химии MNDO [6] в рамках моделей молекулярных и ионно-вложенных ковалентно-циклических кластеров [4].

Для расчета данных моделей используются методы $a b$ initio, приближение локальной плотности, циклический кластер в вычислительных схемах типа Хюккеля, расширенный метод Хюккеля и другие. В рамках полуэмпирической схемы расчета MNDO для однослойных борсодержащих нанотрубок с цилиндрической хиральностью была использо- вана модель ионно-встроенного ковалентного циклического кластера (ИВ-КЦК). Циклические граничные условия в направлении оси нанотрубки были наложены на молекулярные орбитали цилиндрической протяженной элементарной ячейки, содержащей 96 атомов.

В нашем случае размеры протяженной элементарной ячейки $R_{0}$ были выбрано так, чтобы моделировалось взаимодействие вплоть до третьей сферы соседних атомов включительно, что более точно позволяет учесть кривизну нанотрубок.

Взаимодействие атома кислорода было смоделировано для внешней поверхности однослойных нанотрубок нитрида бора $(\mathrm{BN})$ и бороуглеродных нанотрубок типа $\mathrm{BC}_{n}$, где $n=3$. Мы исследовали три структурные модификации трубок $\mathrm{BC}_{3}$ в которых бор и атомы углерода занимают разные позиции, так называемые трубки $\mathrm{BC}_{3}$ типа $\mathrm{A}, \mathrm{B}$ или С. Протяженные элементарные ячейки этих модификаций ВС (см. рис. 1). Были рассчитаны особенности и основные характеристики взаимодействия атома кислорода, присоединявшегося на по- 
верхность нанотрубки типа $\mathrm{BN}(6,6)$ и нанотрубки типа $\mathrm{BC}_{3}(6,0)$.

Нами проведены расчеты для пяти вариантов расположения атома кислорода над поверхностью для всех перечисленных выше типов и модификаций нанотрубок (рис. 2): I) когда атом расположен над центром шестиугольника на поверхности трубки, II) и III) когда он находится над атомами бора, углерода или азота в этих типах нанотрубок, IV) и $\mathrm{V})$ - когда он находится над центром связи между ближайшими атомами шестиугольника на поверхности трубки.

Моделирование приближения атома к поверхности для каждого из вариантов расположение заключалось в постепенном приближении (с шагом 0,1 А). Для первого ва- рианта расположения (атом О к центру гексагона на поверхности $\mathrm{BN}$ или $\mathrm{BC}_{3}$ нанотрубки) движение проходило перпендикулярно поверхности, вдоль воображаемой оси, проведенной через центр шестиугольника. В ходе исследования были построены графики, показывающие изменение энергии системы в зависимости от положения атома, относительно поверхности. Анализ результатов показал, что только на поверхности бороуглеродного тубулена типа А возможна адсорбция атомарного кислорода. На рисунке 3 отображен график зависимости энергии системы описанного процесса.

Аналогичным образом, мы смоделировали процесс адсорбции кислорода на позиции II и III: атом О приближали шаг за ша-

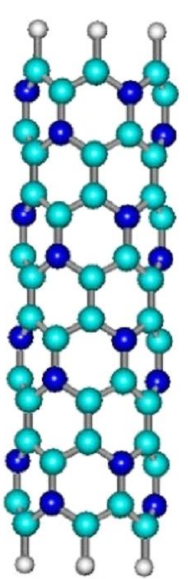

a

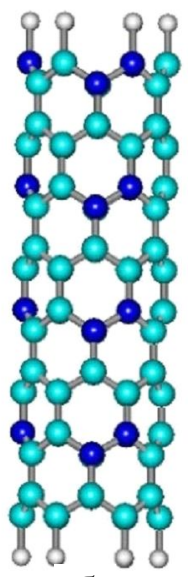

6

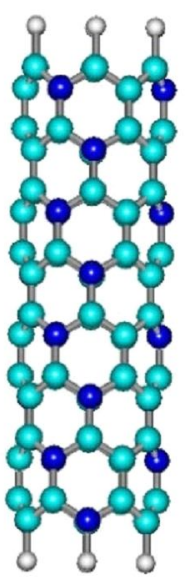

B

\section{- atom of hydrogen \\ - atom of carbon \\ - - atom of boron}

Рис. 1. Варианты периодического расположения атомов бора и углерода для различных структурных модификаций бороуглеродных нанотубуленов типа $\mathrm{BC}_{3}(6,0)$ : $a$ - тип А; $\sigma$ - тип $\mathrm{B} ;$ в - тип С<smiles>O=C1C2CCC3CCC4CCC5CCC6CCC(C1C4CC2)C6C35</smiles><smiles></smiles><smiles>OC12C3CCC4CCCC5CCC6CCC(CCC1CC3)C2C6C54</smiles>

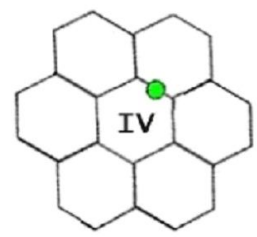<smiles>OC1CC2CCC3CCC4CCC5CCC6CCC1C2C3C4C56</smiles>

Рис. 2. Места дислокации атома кислорода над поверхностью нанотрубки для изучения механизма адсорбции 
гом к выбранному атому (B, C или N) на поверхности бор-углеродной или бор-нитридной нанотрубки. Благодаря полученным значениям, были построены энергетические кривые адсорбции, проанализировав которые выяснили, что адсорбция кислорода возможна на поверхности $\mathrm{BN}$-нанотрубок и нанотрубок $\mathrm{BC}_{3}$ типа $\mathrm{A}$, о чем свидетельствует наличие явного минимума на кривых. Расстояние, на котором наблюдается минимальная энергия взаимодействия, соответствует случаю физсорбции атома кислорода. Моделирование адсорбции атома кислорода на поверхности выбранных типов нанотрубок для положений IV, V проводилось пошаговым приближением (с шагом $0,1 \AA$ ) атома кислорода к центру связи $\mathrm{BN}$ или BC между атомами гексагона поверхности трубок, как показано на рисунке 2. Результаты проведенных расчетов указывают на возможность адсорбции кислорода только на поверхности BN-нанотрубок и нанотрубок $\mathrm{BC}_{3}$ типа А для положений II и III, IV и V. Геометрические параметры и энергии взаимодействия для BN- и $\mathrm{BC}_{3}$-нанотрубок указаны в таблице 1 .

Проведенный анализ распределения электронной плотности в системе показал, что во всех случаях произошел перенос электронной плотности на атомы поверхности трубки от атома кислорода. Это является обоснованием того, что помимо слабого Ван-дерВаальсова взаимодействия, возникает кулоновское взаимодействие, играющее важную роль в данном процессе.

Таким образом, только для нанотрубок $\mathrm{BC}_{3}$ типа Адля позиций $\mathrm{I}-\mathrm{V}$ и $\mathrm{BN}$-нанотрубок

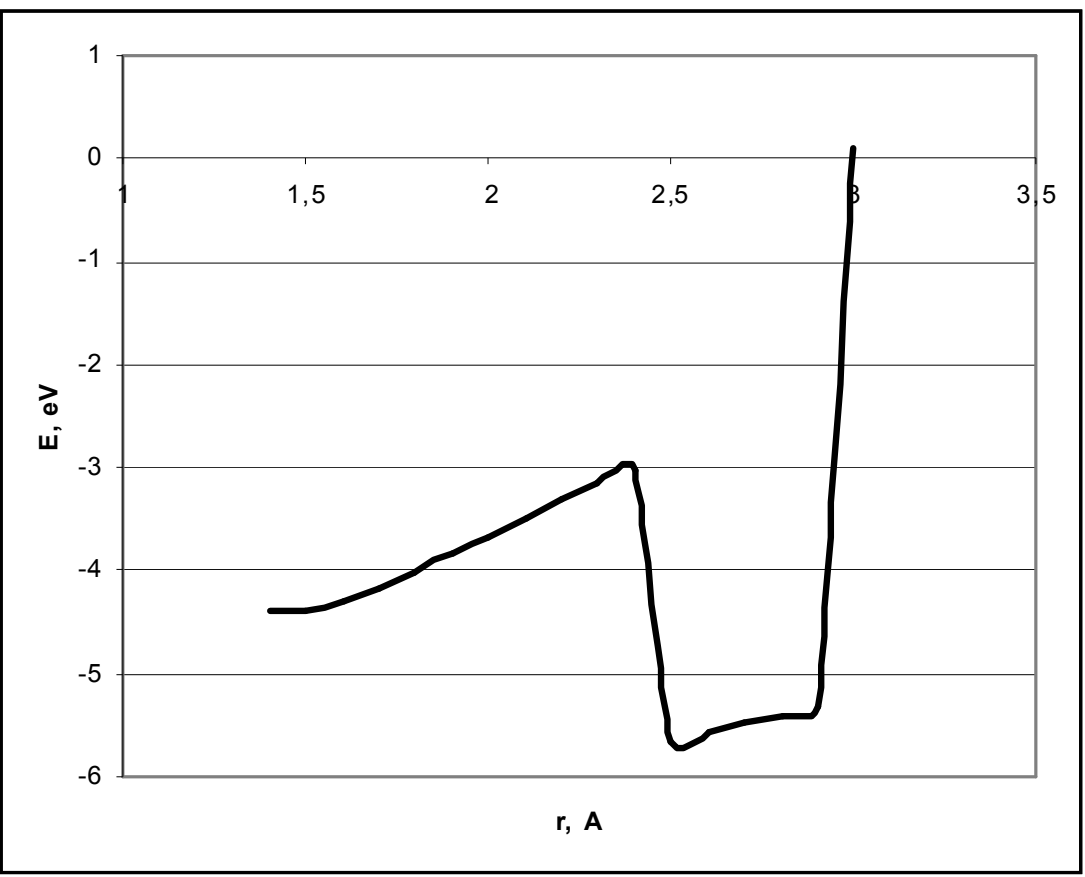

Рис. 3. График зависимости энергии системы нанотрубка-кислород в зависимости от положения атома О относительно поверхности нанотубулена $\mathrm{BC}_{3}$ типа $\mathrm{A}$

Таблица 1

Результаты изучения механизма адсорбции атома кислорода на поверхности BN- и $\mathrm{BC}_{3}$-нанотрубок для пяти положений атома О по отношению к поверхности нанотрубок,

где $E_{\text {аd }}-$ энергия адсорбции; $r_{\text {ад }}$ - расстояние адсорбции

\begin{tabular}{|l|c|c|c|c|c|c|c|c|c|}
\hline & $\begin{array}{c}\mathrm{BN} \\
(\mathrm{II})\end{array}$ & $\begin{array}{c}\mathrm{BN} \\
(\mathrm{III})\end{array}$ & $\begin{array}{c}\mathrm{BN} \\
(\mathrm{IV})\end{array}$ & $\begin{array}{c}\mathrm{BN} \\
(\mathrm{V})\end{array}$ & $\begin{array}{c}\mathrm{BC}_{3} \text { тип } \\
(\mathrm{I})\end{array}$ & $\begin{array}{c}\mathrm{BC}_{3} \text { тип } \mathrm{A} \\
(\mathrm{II})\end{array}$ & $\begin{array}{c}\mathrm{BC}_{3} \text { тип } \mathrm{A} \\
(\mathrm{III})\end{array}$ & $\begin{array}{c}\mathrm{BC}_{3} \text { тип } \mathrm{A} \\
(\mathrm{IV})\end{array}$ & $\begin{array}{c}\mathrm{BC}_{3} \text { тип } \mathrm{A} \\
(\mathrm{V})\end{array}$ \\
\hline$r_{\text {ад }}, \dot{\mathrm{A}}$ & 2,9 & 2,8 & 2,6 & 2,7 & 2,5 & 2,8 & 2,9 & 2,7 & 2,9 \\
\hline$E$, эВ & 2,49 & 2,48 & 2,58 & 2,48 & 5,67 & 6,71 & 7,96 & 6,57 & 7,94 \\
\hline
\end{tabular}


для позиций II-V возможна адсорбция атомарного кислорода на внешней поверхности нанотрубок, углеродные нанотрубки $\mathrm{BC}_{3}$ типов В и С не способны образовывать адсорбционные комплексы с атомом кислорода.

В данной работе мы исследовали возможность адсорбции молекулы кислорода на поверхности борных (типа armchair [6,6]), боруглеродных $\mathrm{BC}_{3}$ (типа zig-zag [6,0]), и бор-нитридные BN (типа armchair [6,6]) нанотрубки. Ранее была доказана возможность адсорбции атомарного кислорода на их поверхности [3; 1]. На рис. 4 показаны восемь положений молекулы кислорода $\mathrm{O}_{2}$ на поверхности трубок.
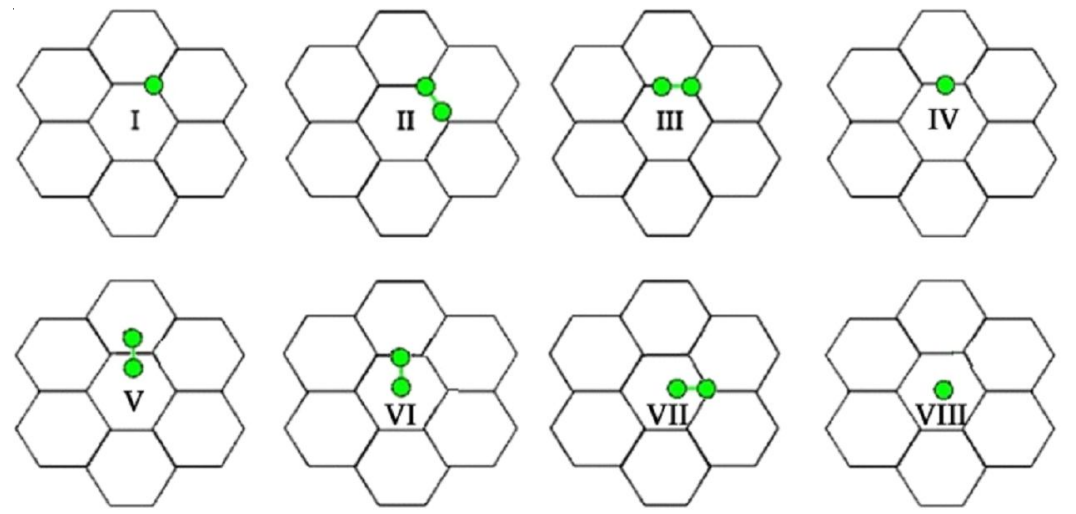

Рис. 4. Положение молекулы кислорода на поверхности трубок

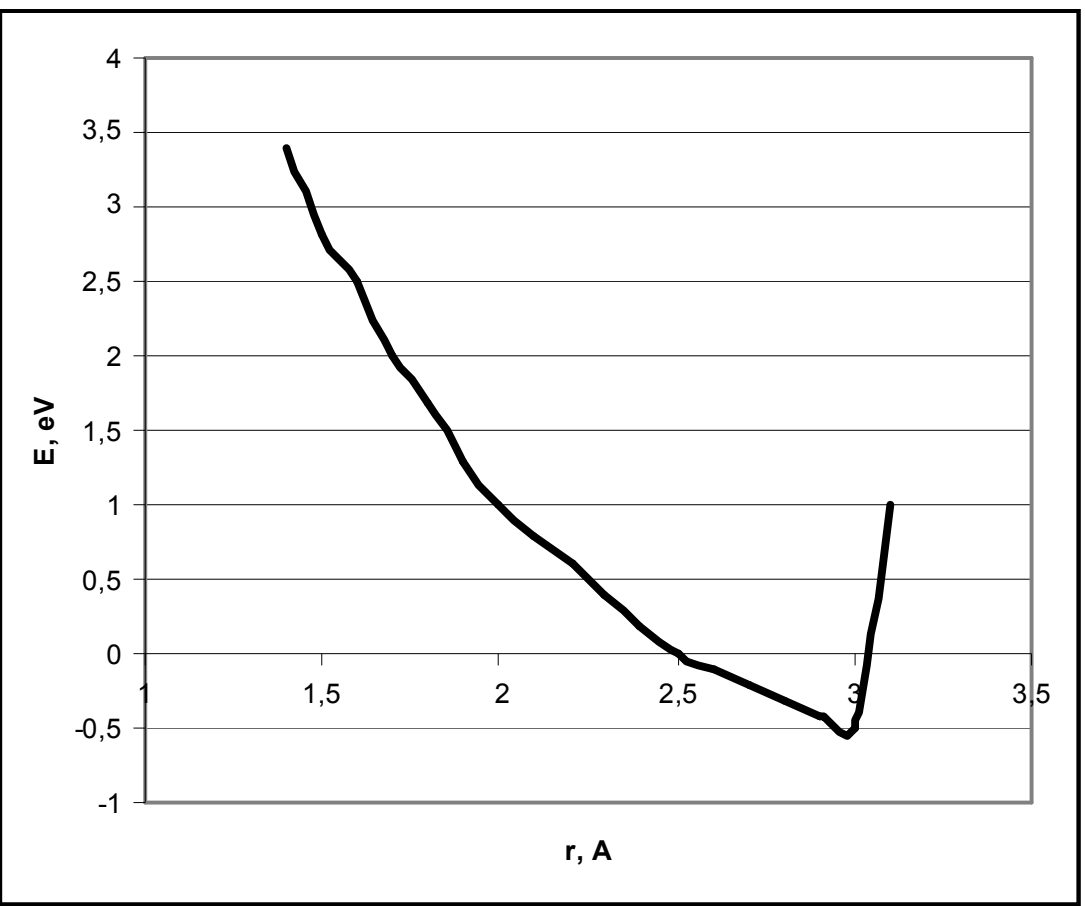

Рис. 5. Кривые потенциальной энергии для положения I поглощения молекулы кислорода на внешней поверхности борных нанотрубок $(6,6)$ 
Поскольку минимумов более не наблюдается, на поверхности других трубок адсорбция маловероятна.

Был смоделирован процесс адсорбции для позиции II, используя пошаговое приближение молекулы кислорода к поверхности нанотрубок всех выбранных типов. Движение молекулы направлено параллельно связям В-, ВС или -N (рис. 4). На основе анализа энергетических кривых выявлено, что адсорбция молекулы кислорода не происходит на поверхности трубки из нитрида бора. Для боруглеродных нанотрубок был реализован процесс адсорбции в этом положении, что проявляется в наличии на кривой минимальной энергии, показанной на рис. $6, \mathrm{c} r_{\mathrm{ad}}=1,7 \AA$, $E_{\mathrm{ad}}=11,34$ эВ, с молекулой преодоление потенциального барьера высотой 3,5 эВ. Анализ энергетической кривой, соответствующей адсорбции $\mathrm{O}_{2}$ на поверхности борного трубки для положения II, показал минимум при энергии 8,39 эВ, что соответствует расстоянию $r_{\text {ad }}=2,4 \AA$ между молекулой кислорода и поверхность трубки. Для достижения этого состояния размер молекулы должен быть достаточно большим, чтобы преодолеть высоту потенциального барьера 14,45 эВ, что делает адсорбцию кислорода в этом положении проблематичной.

Наши расчеты показали, что в борных и борнитридных нанотрубках адсорбция $\mathrm{O}_{2}$ в позиции III невозможна. Но минимум, сопровождающийся энергетической прямой, подтверждает существование адсорбции для боруглеродных нанотрубок типа А. Данному минимуму присуще значение $E_{\mathrm{AD}}=11,59$ эВ и $r_{\mathrm{AD}}=1,5 \AA$, высота потенциального барьера на пути молекулы составляет 1,4 эВ, что достаточно мало, чтобы преодолеть. В положении IV происходит физическая адсорбция $\mathrm{BC}_{3}$ нанотрубкой. Невозможность адсорбции молекулы кислорода наблюдается при взаимодействии с поверхностью нанотрубки в положении V, а в положении VI она образует адсорбционный комплекс «молекула $\mathrm{O}_{2}-$ нанотрубка $\mathrm{BC}_{3}$ ». Адсорбция молекулы кислорода на поверхности бора и нанотрубок нитрида бора наблюдается при положении VII. При преодолении молекулы высоты потенциального барьера, равным 3,2 эВ, возникает молекулярная адсорбция кислорода в положении VIII только для $\mathrm{BC}_{3}$-нанотрубок. Основные геометрические и энергетические характеристики этих процессов представлены в таблице 2.

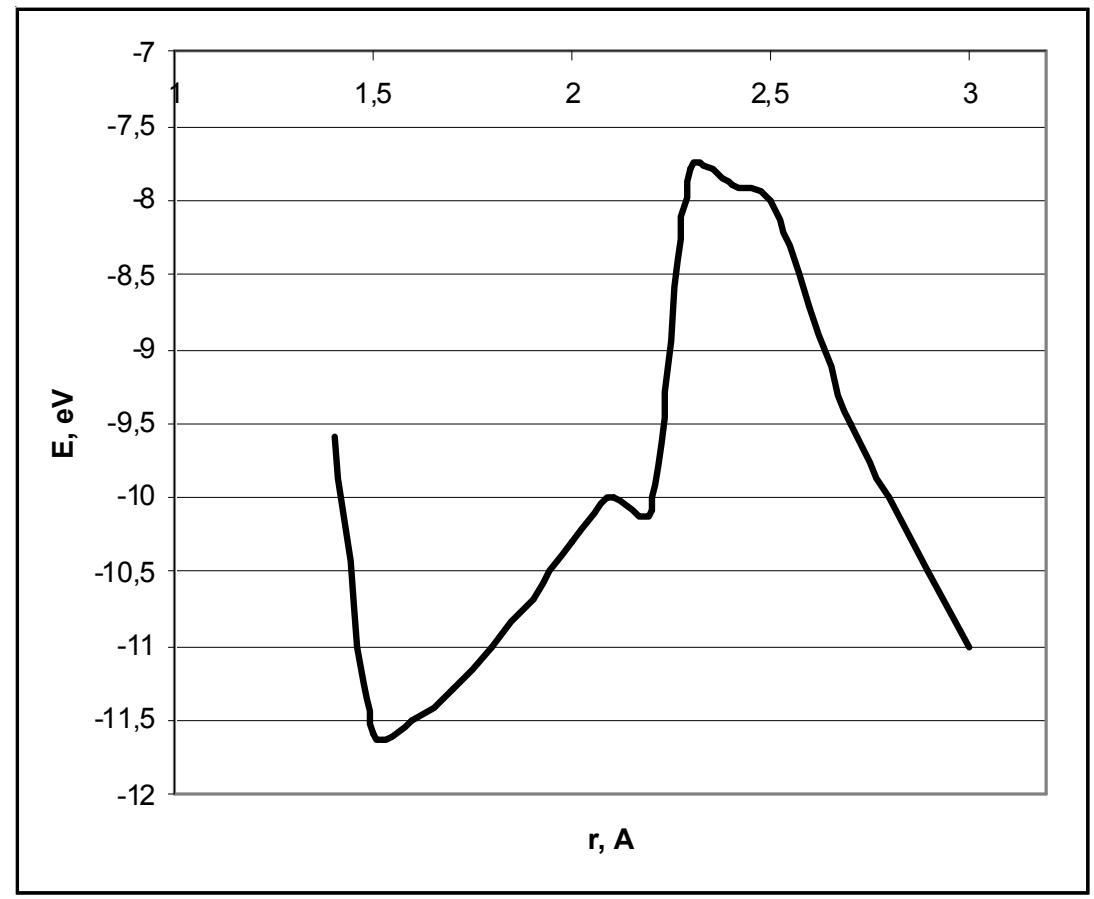

Рис. 6. Кривая потенциальной энергии адсорбции молекулы кислорода на внешней поверхности $\mathrm{BC}_{3}$-нанотрубки типа А для позиции II 
Исследование взаимодействия кислорода с поверхностью боросодержащих нанотрубок

Таблийа 2

Основные характеристики адсорбции молекулярного кислорода на поверхности В, ВС 3 и ВN нанотрубок для различных положений (I-VIII) молекулы кислорода на поверхности трубок: $E_{\text {ad }}-$ энергия адсорбции, $r_{\text {ad }}-$ расстояние адсорбции

\begin{tabular}{|l|c|c|c|c|c|c|c|c|c|}
\hline & $\begin{array}{c}\mathrm{BN} \\
(\mathrm{VII})\end{array}$ & $\begin{array}{c}\mathrm{B} \\
(\mathrm{I})\end{array}$ & $\begin{array}{c}\mathrm{B} \\
(\mathrm{II})\end{array}$ & $\begin{array}{c}\mathrm{B} \\
(\mathrm{VII})\end{array}$ & $\begin{array}{c}\mathrm{BC}_{3} \text { тип } \mathrm{A} \\
(\mathrm{II})\end{array}$ & $\begin{array}{c}\mathrm{BC}_{3} \text { тип } \mathrm{A} \\
(\mathrm{III})\end{array}$ & $\begin{array}{c}\mathrm{BC}_{3} \text { тип } \\
(\mathrm{IV})\end{array}$ & $\begin{array}{c}\mathrm{BC}_{3} \text { тип } \mathrm{A} \\
(\mathrm{VI})\end{array}$ & $\begin{array}{c}\mathrm{BC}_{3} \text { тип } \mathrm{A} \\
(\mathrm{VIII})\end{array}$ \\
\hline$r_{\mathrm{ad}}, \AA$ & 2,9 & 2,9 & 2,4 & 2,5 & 1,7 & 1,5 & 2,7 & 1,9 & 1,7 \\
\hline$E$, эВ & 4,25 & 0,49 & 8,39 & 0,69 & 11,34 & 11,59 & 13,03 & 9,80 & 10,44 \\
\hline
\end{tabular}

Изученный механизм адсорбции атома кислорода на поверхности $\mathrm{B}, \mathrm{BC}_{3}$ и $\mathrm{BN}$ нанотрубок позволяет сделать вывод о том, что несмотря на расположение атома кислороданад поверхностью $\mathrm{BC}_{3}$ нанотрубки, его адсорбция возможна. Для BN-нанотрубок адсорбция не может быть реализована в случае, когда атом кислорода расположен выше центра поверхности гексагона нанотрубки. В остальных случаях адсорбция кислорода на бор-нитридную трубку возникает, причем физическая $\mathrm{BC}_{3}$ нанотрубки оказались наиболее эффективным адсорбентом кислорода ввиду образования большего количества возможных адсорбционных комплексов.

\section{СПИСОК ЛИТЕРАТУРЫ}

1. Адсорбция легких атомов на поверхности борных нанотруб / И. В. Запороцкова, Е. В. Перевалова, С. В. Борознин, А. О. Степанова // Технология металлов. -2010 . - № 10. - С. 25.

2. Дьячков, П. Н. Электронные свойства и применение нанотрубок : [монография] / П. Н. Дьячков. 4-е изд. (эл.). - М. : Лаборатория знаний, 2020. - 491 с.

3. Запороцкова, И. В. Борные нанотрубки: полуэмпирические исследования строения и некоторых физико-химических свойств / И. В. Запороцкова, Е. В. Перевалова // Технология металлов. 2009. - № 9. - С. 25-29.

4. Литинский, А. О. Модель ионно-встроенного ковалентно-циклического кластера в MNDOрасчетах межмолекулярных взаимодействий в гетерогенных системах / А. О. Литинский, Н. Г. Лебедев, И. В. Запороцкова // Журнал физической химии. $-1995 .-$ Т. 69, № 1. - С. 189.

5. Chiral tubules of hexagonal $\mathrm{BC}_{2} \mathrm{~N}$ / Y. Miyamoto, A. Rubio, M. L. Cohen, S. G. Louie // Physical Review. - 1994. - Vol. 50. - P. 4976-4979.
6. Dewar, M. J. S. Ground states of molecules. The MNDO method. Approximations and Parameters / M. J. S. Dewar, W. Thiel // J. Amer. Chem. Soc. 1977. - Vol. 99. - P. 4899-4906.

7. Recent trends in gas sensing via carbon nanomaterials: outlook and challenges / P. Dariyal, S. Sharma, G. S. Chauhan, B. P. Singh, S. R. Dhakate // Nanoscale Advances. - 2021. - Vol. 3, № 23. - P. 6514 6544.

8. Rubio, A. Theory of graphitic boron nitride nanotubes / A. Rubio, J. L. Corkill, and M. L. Cohen // Phys. Rev. B. - 1994. - Vol. 49. - P. 5081.

\section{REFERENCES}

1. Zaporotskova I.V., Perevalova E.V., Boroznin S.V., Stepanova A.O. Adsorbcija legkih atomov na poverhnosti bornyh nanotrub [Adsorption of Light Atoms on the Surface of Boron Nanotubes]. Tehnologija metallov [Process Metallurgy], 2010, no. 10, p. 25.

2. D'jachkov P.N. Jelektronnye svojstva $i$ primenenie nanotrubok: monografiya [Electronic Properties and Use of Nanotubes. Monograph]. Moscow, Laboratorija znanij Publ., 2020. 491 p.

3. Zaporotskova I.V., Perevalova E.V. Bornye nanotrubki: polujempiricheskie issledovanija stroenija i nekotoryh fiziko-himicheskih svojstv [Boric Nanotubes: Semi-Empirical Studies of the Structure and Some Physicochemical Properties]. Tehnologija metallov [Process Metallurgy], 2009, no. 9, pp. 25-29.

4. Litinskij A.O., Lebedev N.G., Zaporotskova I.V. Model' ionno-vstroennogo kovalentnociklicheskogo klastera v MNDO-raschetah mezhmolekuljarnyh vzaimodejstvij $\mathrm{v}$ geterogennyh sistemah [Model of Ion-Built Covalent-Cyclic Cluster in MNDO Calculations of Intermolecular Interactions in Heterogeneous Systems]. Zhurnal fizicheskoj himii [Journal of Physical Chemistry], 1995, vol. 69, no. 1, p. 189. 
5. Miyamoto Y., Rubio A., Cohen M.L., Louie S.G. Chiral Tubules of Hexagonal $\mathrm{BC}_{2} \mathrm{~N}$. Physical Review, 1994, vol. 50, pp. 4976-4979.

6. Dewar M.J.S, Thiel W. Ground States of Molecules. The MNDO Method. Approximations and Parameters. J. Amer. Chem. Soc., 1977, vol. 99, pp. 48994906.
7. Dariyal P., Sharma S., Chauhan G.S., Singh B.P., Dhakate S.R. Recent Trends in Gas Sensing Via Carbon Nanomaterials: Outlook and Challenges. Nanoscale Advances, 2021, vol. 3, no. 23, pp. 6514-6544.

8. Rubio A., Corkill J.L., Cohen M.L. Theory of Graphitic Boron Nitride Nanotubes. Phys. Rev. B., 1994, vol. 49 , p. 5081.

\title{
STUDY OF OXYGEN INTERACTION WITH SURFACE OF BORON-CONTAINING NANOTUBES
}

\author{
Sergey V. Boroznin \\ Candidate of Sciences (Physics and Mathematics), \\ Acting Head of the Department of Forensic Science and Physical Materials Science, \\ Volgograd State University \\ boroznin@volsu.ru \\ Prosp. Universitetsky, 100, 400062 Volgograd, Russian Federation
}

\section{Irina V. Zaporotskova}

Doctor of Sciences (Physics and Mathematics), Professor,

Director of the Institute of Priority Technologies,

Volgograd State University

zaporotskova@volsu.ru

Prosp. Universitetsky, 100, 400062 Volgograd, Russian Federation

\section{Natalia P. Boroznina}

Doctor of Sciences (Physics and Mathematics), Associate Professor, Department of Forensic Science and Physical Materials Science,

Volgograd State University

boroznina.natalya@volsu.ru

Prosp. Universitetsky, 100, 400062 Volgograd, Russian Federation

\section{Daria A. Zvonareva}

Assistant, Department of Forensic Science and Physical Materials Science,

Volgograd State University

zvonareva@volsu.ru

Prosp. Universitetsky, 100, 400062 Volgograd, Russian Federation

\section{Pavel A. Zaporotskov}

Candidate of Sciences (Physics and Mathematics), Associate Professor,

Department of Forensic Science and Physical Materials Science,

Volgograd State University

zaporotskov@volsu.ru

Prosp. Universitetsky, 100, 400062 Volgograd, Russian Federation 
Evgeniya E. An

Student, Department of Forensic Science and Physical Materials Science,

Volgograd State University

NIm-201291179@volsu.ru

Prosp. Universitetsky, 100, 400062 Volgograd, Russian Federation

\begin{abstract}
Studies of semiconductor carbon nanotubes show that they are extremely sensitive to the chemical environment, and the effects of oxygen drastically change their properties. It has been found that narrow-zone semiconductor carbon tubes can be converted into an apparent metal by such action. Since other types of nanotubes, such as boron-carbon nanotubes of the $\mathrm{BC}_{3}$ type and boron-nitride $\mathrm{BN}$ nanotubes, are of great interest, it seems important to investigate whether they are capable of absorbing atomic and molecular oxygen. The study was conducted using the MNDO calculation method within molecular and ionnested covalent-cyclic cluster models. The results of the study of the interaction of atomic and molecular oxygen with the external surfaces of boron-carbon $\left(\mathrm{BC}_{3}\right)$, boron-nitride $(\mathrm{BN})$ and boron nanotubes are considered: chair $(n, n)$ and zigzag $(n, 0)$ type. The study was performed by the MNDO method as part of a covalent-cyclic cluster model with embedded ions. Optimal geometry of adsorption complexes is determined and their main electronic and energy properties are described. Boron-carbon nanotubes have been shown to be better oxygen adsorbents than other types of nanotubes considered.
\end{abstract}

Key words: ab initio, carbon nanotubes, adsorption, boron-carbon nanotubes, oxygen, boron-nitride nanotubes, oxidation, MNDO. 